\title{
AN OBSERVATIONAL STUDY OF CARDIAC INVOLVEMENT IN COPD PATIENTS AND IT'S CORRELATION WITH SEVERITY OF THE DISEASE
}

\section{Prapti Shinde ${ }^{1}$, A. B. Khare ${ }^{* 2}$, Manoj Waghmare ${ }^{3}$, Marcia Waran ${ }^{4}$, Arun Tyagi ${ }^{5}$.}

${ }^{1}$ Resident, DVVPF's Medical College, Vadgaon Gupta, Post-MIDC, Ahmednagar, Maharashtra, India.

${ }^{* 2}$ Associate Professor, Department of Medicine, DVVPF's Medical College, Vadgaon Gupta, PostMIDC, Ahmednagar, Maharashtra, India.

${ }^{3}$ Assistant Professor, Pulmonary Medicine, DVVPF's Medical College, Vadgaon Gupta, Post-MIDC, Ahmednagar, Maharashtra, India.

${ }^{4}$ Professor, Department of Medicine, DVVPF's Medical College, Vadgaon Gupta, Post-MIDC, Ahmednagar, Maharashtra, India.

${ }^{5}$ Professor and Head, Department of Medicine, DVVPF's Medical College, Vadgaon Gupta, PostMIDC, Ahmednagar, Maharashtra, India.

\section{ABSTRACT}

Introduction: The course of Chronic Obstructive Pulmonary Disease (COPD) is marked by various systemic manifestations and complications. Cardiac involvement is one of those manifestations. Pulmonary vascular disease and its impact on right ventricular function, higher incidence of myocardial infarction and arrhythmias are well known complications of COPD and correlate inversely with survival.

Aim: To study cardiac involvement in COPD patients and it's correlation with severity of the disease.

Methods: This observational study was conducted in the medicine department of a tertiary care hospital in western Maharashtra. Data of 100 patients diagnosed and their cardiac status assessed on the basis of clinical findings, radiological changes and spirometry, electrocardiography and echocardiography. All patients were analyzed for cardiac involvement based on symptomatology, ECG and 2D-ECHO results.

Results: Of 100 COPD patients, 8 patients were GOLD class 1 (mild), 30 in class 2 (moderate), 50 in class 3 (severe) and 12 patients belonged to GOLD class 4 (very severe). Cardiovascular complications were found in 52 patients out of 100 . Of these, pulmonary hypertension was found in $41 \%$, IHD in $21 \%$, cor pulmonale in $18 \%$ and arrhythmias were found in $9 \%$ of which supraventricular arrhythmias were seen in $66.66 \%$ and ventricular arrhythmia in33.33\%.

Conclusion: Our study showed that cardiac complications may be seen in mild to moderate COPD as well. They are difficult to diagnose because of common symptomatology. It is therefore prudent to carry out ECG and 2DECHO at the time of initial diagnosis for early detection and for better management of these patients.

KEY WORDS: Chronic Obstructive Pulmonary Disease (COPD), Pulmonary Hypertension, Ventricular dysfunction, 2D-ECHO, ECG.

Address for correspondence: Brig (Dr) A.B. Khare (Retd), Associate Professor, Department of Medicine, DVVPF's Medical College, Vadgaon Gupta, Post-MIDC, Ahmednagar - 414111, Maharashtra, India. Mobile no.+919451729669, E-Mail: dr.ab.khare@gmail.com

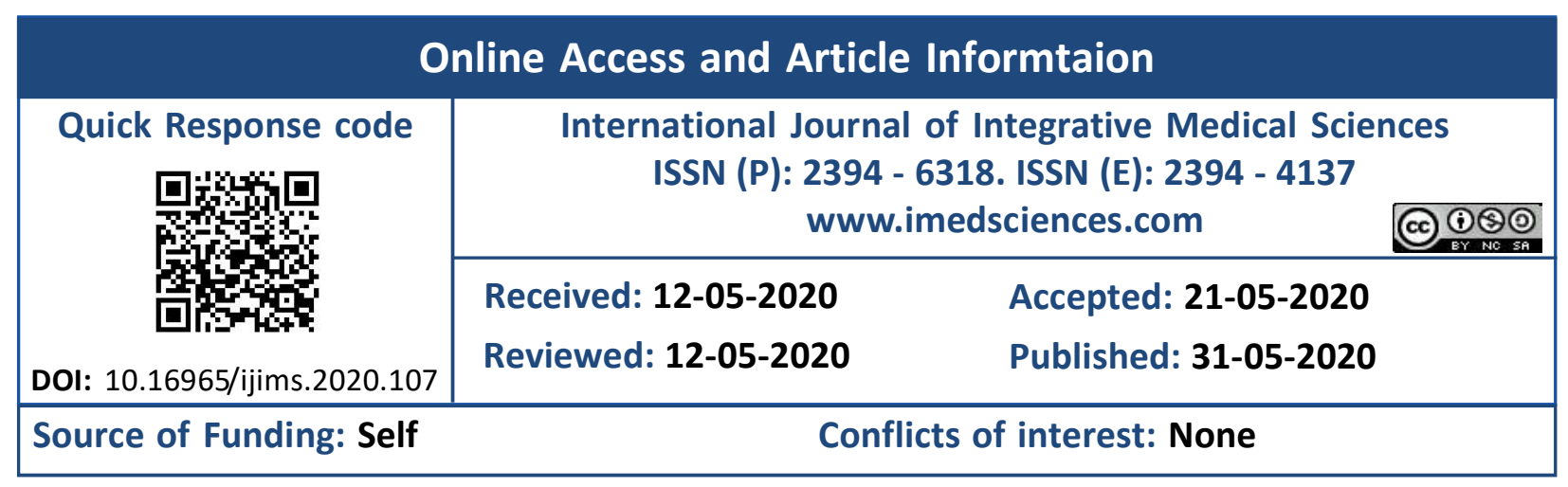




\section{INTRODUCTION}

Chronic Obstructive Pulmonary Disease (COPD) was predicted to be the third leading cause of death by the year 2030 as per analysis of world health statistics 2008 published by WHO on 20th May 2008. However, according to the Global Burden of Disease 2018, COPD is already the third leading cause of death worldwide [1]. It is expected to become leading cause of death worldwide in little more than a decade [2]. Estimated prevalence of the disease is between $6.5 \%$ and $7.7 \%$ [3]. The number of COPD in India increased from 28.1 million in 1990 to 55.3 million cases in 2016 [4]. The course of COPD is complicated by various systemic manifestations and complications. Cardiac involvement is one of those manifestations and is the most common cause of death in COPD $[5,6]$. Pulmonary vascular disease and its impact on right ventricular function, higher incidence of myocardial infarction and arrhythmias are well known complications of COPD and correlate inversely with survival [7]. The cardiac involvement occurs most likely due to common risk factors like aging, cigarette smoking, inactivity and persistent low-grade pulmonary and systemic inflammation [8]. This increases the overall morbidity and mortality in COPD. Also, cardiac disease contributes to severity of COPD as both are responsible for frequent hospitalization and death. Furthermore, common symptoms found in the two diseases such as breathlessness, chest pain, cough and easy fatigability create difficulty in diagnosis of co-existing cardiac disease/complication. Atrial fibrillation is frequent cardiac arrhythmia encountered in COPD patients being directly related to declining FEV1. It could be the trigger or consequence of acute exacerbation of COPD [9].

Out of these cardiac manifestations, pulmonary arterial hypertension (PAH) and chronic cor pulmonale (COR-P) are well known major complications of COPD. In the late stages of COPD, right ventricular dysfunction is commonly seen increasing in severity \& frequency of hospitalization. It can further worsen dyspnoea, reduce the exercise tolerance and decline the functional status. Cardiac arrhythmias, ischemic heart disease, myocardial infarction, and congestive heart failure also confound the course of events in patients of COPD.

AIMS: To analyze the frequency of cardiac involvement in cases of COPD and to find out the correlation with the severity of COPD, if any.

\section{METHODOLOGY}

This observational study was conducted at the medicine department of tertiary care hospital in central Maharashtra. Ethical committee approval was taken. Data of 100 patients diagnosed as COPD on the basis of clinical, radiological and spirometry were analyzed for cardiac manifestation with the help of symptoms, ECG and 2 D-ECHO.

Inclusion Criteria Patients diagnosed as COPD based on clinical history, chest radiography and spirometry.

Exclusion Criteria Patients with history of chronic lung disease other than COPD, hypertension, preexisting cardiac disease, unable to perform spirometry.

Sampling: All patients meeting inclusion and exclusion criteria were enrolled in the study and were categorized into GOLD class according to FEV1 value on spirometry. Data including clinical features, ECG and 2-D ECHO was collected. Pulmonary hypertension patients were further classified into mild $(30-50 \mathrm{mmHg})$, moderate $(50-70 \mathrm{mmHg})$ and severe $(>70 \mathrm{mmHg})$ [10]. ACC/AHA 2011 criteria were used for diagnosis of IHD [11]. Data analysis was done using mean, median, average, SD, $\mathrm{P}$ value and $\mathrm{Chi}$ square test.

\section{RESULTS}

Age distribution in our study ranged from 50 years to 80 years with a mean age of $64.26 \pm$ 16.52 years. In our study we found male preponderance. There were 89 males and $11 \mathrm{fe}$ males with male to female ratio of $8.09: 1$. Out of 100 cases of COPD, 8 patients had mild, 30 moderate, 50 severe and 12 patients had very severe COPD. Fifty-two patients out of 100 patients studied had cardiac manifestations. Fortyone patients were diagnosed with pulmonary hypertension. The total number and percentage of pulmonary hypertension (PAH) was 1 $(12.5 \%)$ in mild, $30(13.33 \%)$ in moderate, 26 $(52 \%)$ in severe and $10(83.3 \%)$ in very severe cases of COPD. Twenty-one percent patients 
were diagnosed as IHD on the basis of ECG changes, and $9 \%$ had arrhythmias, of whom $66.66 \%$ had supraventricular arrhythmias (atrial fibrillation and multifocal atrial tachycardia) and $33.33 \%$ had ventricular premature beats.

Table 1: Classification of COPD Patients based on Airflow Limitation.

\begin{tabular}{|l|c|c|}
\hline \multicolumn{1}{|c|}{ GOLD Class } & Severity & No. of patients \\
\hline $\mathbf{1}$ (FEV1> 80\%) & Mild & $8(8 \%)$ \\
\hline $\mathbf{2}$ (FEV1 $\mathbf{5 0 - 8 0 \% )}$ & Moderate & $30(30 \%)$ \\
\hline $\mathbf{3}$ (FEV1 $\mathbf{3 0 - 5 0 \% )}$ & Severe & $50(50 \%)$ \\
\hline $\mathbf{4}$ (FEV1 <30\%) & Very severe & $12(12 \%)$ \\
\hline
\end{tabular}

Table 2: Frequency of Cardiac Manifestations and their association with severity of COPD.

\begin{tabular}{|l|c|c|c|c|}
\hline \multicolumn{1}{|c|}{ GOLD class } & $\begin{array}{c}\text { Pulmonary } \\
\text { Hypertension }\end{array}$ & COR-P & IHD & Arrhythmias \\
\hline $\mathbf{1}$ (mild) & $1(12.5 \%)$ & - & $1(12.5 \%)$ & 0 \\
\hline $\mathbf{2}$ (moderate) & $4(13.33 \%)$ & $3(10 \%)$ & $1(3.33 \%)$ & $1(3.33 \%)$ \\
\hline 3 (severe) & $26(52 \%)$ & $8(16 \%)$ & $9(18 \%)$ & $3(6 \%)$ \\
\hline 4 (very severe) & $10(83.3 \%)$ & $7(58.33 \%)$ & $10(83.33 \%)$ & $5(41.66 \%)$ \\
\hline \multicolumn{5}{|c|}{$X^{2}=12.58, p=0.042$, Significant } \\
\hline & 41 & 18 & 21 & 9 \\
\hline
\end{tabular}

Table 3: Incidence of Pulmonary Hypertension and its association with Severity of Airflow Limitation.

\begin{tabular}{|l|c|c|c|c|}
\hline \multicolumn{1}{|c|}{ GOLD Class } & $\begin{array}{c}\text { Mild PH } \\
(30-50 \mathrm{mmHg})\end{array}$ & $\begin{array}{c}\text { Moderate PH } \\
(\mathbf{5 0 - 7 0} \mathbf{m m H g})\end{array}$ & $\begin{array}{c}\text { Severe PH } \\
(>70 \mathrm{mmHg})\end{array}$ & Total \\
\hline 1 (mild) & $1(100 \%)$ & 0 & 0 & 1 \\
\hline 2 (moderate) & $3(75 \%)$ & $1(25 \%)$ & 0 & 4 \\
\hline 3 (severe) & $2(7.69 \%)$ & $11(42.30 \%)$ & $13(50 \%)$ & 26 \\
\hline 4 (very severe) & $4(40 \%)$ & $4(40 \%)$ & $2(20 \%)$ & 10 \\
\hline Total & 10 & 16 & 15 & 41 \\
\hline \multicolumn{5}{|c|}{$x^{2}=14.58, p=0.002$, Significant } \\
\hline
\end{tabular}

Table 4: Frequency of Arrhythmias in COPD patients.

\begin{tabular}{|c|c|c|}
\hline Type of arrhythmia & $\begin{array}{c}\text { Number of } \\
\text { patients (N=9) }\end{array}$ & Percentage \\
\hline Supraventricular & $\mathrm{N}=6$ & $66.60 \%$ \\
\hline Atrial fibrillation & 5 & $83.33 \%$ \\
\hline Multifocal atrial tachycardia & 1 & $16.66 \%$ \\
\hline Atrial Premature Beats & - & - \\
\hline Ventricular & $\mathrm{N}=3$ & 33.33 \\
\hline Ventricular Premature Beats & 3 & $100 \%$ \\
\hline
\end{tabular}

\section{DISCUSSION}

Most of the patients studied had moderate to severe COPD. Out of 100 patients studied, 52 patients had cardiac manifestations. The incidence of PAH among study groups showed that frequency of PAH increased with increasing severity of COPD. Same results were also seen in other studies conducted in India by Sruti Reddy et al [12], NK Gupta et al [13] and Vivek Katiyar et al [14]. COR-P as reflection of pulmonary hypertension was seen in $18 \%$ of COPD patients, occurrence being more in severe and very severe disease. It corresponds to the study conducted by N. K. Gupta et al wherein COR-P was seen in $17.5 \%$ cases [13]. In contrast, Lokendra Dave et al [15] and Kaushal et al [16] found a higher prevalence of COR-P $39.5 \%$ and $32 \%$ cases respectively, probably because the majority of the patients in these studies were from severe and very severe COPD GOLD class.

Twenty-one patients in our study were diagnosed with Ischemic heart Disease and most of them belonged to a severe and very severe group of COPD. Similar results were found in a study by Amit S Gupta et al where $21 \%$ of patients were found to have IHD along with COPD [17]. Nine percent of the patients from the study group had arrhythmias out of which $66.66 \%$ had supraventricular arrhythmias and $33.33 \%$ had premature ventricular complexes. In supraventricular arrhythmias, atrial fibrillation is seen in $83.3 \%$ cases; other patients had multifocal atrial tachycardia and atrial premature beats. The incidence of atrial fibrillation corresponds to studies held in India by Sushil Anturlikar et al [18] and Dabadghao VS et al [19].

\section{CONCLUSION}

Cardiac complications are commonly seen in advanced COPD. Our study showed they can be seen in mild to moderate disease as well. Due to common symptomatology with COPD the cardiac manifestations are difficult to diagnose. It is therefore recommended that routine electrocardiographic and echocardiographic studies be carried out in all COPD patients, at the time of initial diagnosis and periodically thereafter, for early detection, monitoring and better management of cardiac comorbidities in these cases.

\section{REFERENCES}

[1]. Alwan A. Global status report on non-communicable diseases 2010. World Health Organization; 2011.

[2]. Lozano R, Naghavi M, Foreman K, Lim S, Shibuya K, Aboyans V, Abraham J, Adair T, Aggarwal R, Ahn SY, AlMazroa MA. Global and regional mortality from 235 causes of death for 20 age groups in 1990 and 2010: a systematic analysis for the Global Burden - 
of Disease Study 2010. The lancet. 2012 Dec 15;380(9859):2095-128.

[3]. McKay AJ, Mahesh PA, Fordham JZ, Majeed A. Prevalence of COPD in India: a systematic review. Primary Care Respiratory Journal. 2012; 21 (3):31321. DOI: https://doi.org/10.1016/S2214109X(18)30409-1

[4]. Salvi S, Kumar GA, Dhaliwal RS, Paulson K, Agrawal A, Koul PA, Mahesh PA, Nair S, Singh V, Aggarwal AN, Christopher DJ. The burden of chronic respiratory diseases and their heterogeneity across the states of India: the Global Burden of Disease Study 19902016. The Lancet Global Health. 2018 Dec 1;6(12):e1363-74 DOI: https://doi.org/10.1016/ S2214-109X(18)30409-1.

[5]. Mathers CD, Loncar D. Projections of global mortality and burden of disease from 2002 to 2030. Plos med. 2006Nov28;3(11):e442. DOI: https://doi.org/ 10.1371/ journal.pmed.0030442

[6]. Morgan AD, Zakeri R, Quint JK. Defining the relationship between COPD and CVD: what are the implications for clinical practice? Therapeutic Advances in Respiratory Disease. 2018 Jan 19;12: 1753465817750524. doi: 10.1177/175346581775 0524

[7]. McAllister DA, Maclay JD, Mills NL, Leitch A, Reid P, Carruthers R, O'Connor J, McAlpine L, Chalmers G, Newby DE, Clark E. Diagnosis of myocardial infarction following hospitalisation for exacerbation of COPD. European Respiratory Journal. 2012 May 1;39(5):1097-103.DOI:10.1183/09031936. 00124811

[8]. Falk JA, Kadiev S, Criner GJ, Scharf SM, Minai OA, Diaz P. Cardiac disease in chronic obstructive pulmonary disease. Proceedings of the American thoracic society. 2008; 5(4):543-8. DOI: $10.1513 /$ pats.200708-142ET

[9]. Terzano C, Romani S, Conti V, Paone G, Oriolo F, Vitarelli A. Atrial fibrillation in the acute, hypercapnic exacerbations of COPD. Eur Rev Med Pharmacol Sci. 2014 Oct 1; 18(19):2908-17. DOI: https://doi.org/10.2147/COPD.S143691

[10].Chemla D, Castelain V, Humbert M, Hébert JL, Simonneau G, Lecarpentier Y, Hervé P. New formula for predicting mean pulmonary artery pressure using systolic pulmonary artery pressure. Chest. 2004 Oct 1; 126(4):1313-7. DOI: 10.1378/chest.126.4. 1313

[11]. Anderson JL, Adams CD, Antman EM, et al. 2011 ACCF/ AHA Focused Update Incorporated Into the ACC/AHA 2007 Guidelines for the Management of Patients With Unstable Angina/Non-ST-Elevation Myocardial Infarction: a report of the American College of Cardiology Foundation/American Heart Association Task Force on Practice Guidelines [published correction appears in Circulation. 2011 Jun 7;123(22):e627]. Circulation. 2011;123(18):e426 e579. DOI: 10.1161/CIR. Ob013e318212bb8b.
[12]. Reddy S, Rajender RN. Prevalence of pulmonary hypertension in COPD patients: a retrospective observational study. Int J Integrative Med Sci. 2016;3(5):2859. DOI:10.16965/ijims.2016.119

[13].Gupta NK, Agrawal RK, Srivastav AB, Ved ML. Echocardiographic evaluation of heart in chronic obstructive pulmonary disease patient and its corelation with the severity of disease. Lung India: official organ of Indian Chest Society. 2011 Apr;28(2):105. DOI: 10.4103/0970-2113.80321

[14]. Katiyar V, Khare RK. Prevalence of pulmonary hypertension in COPD. International Journal of Advances in Medicine. 2018 Mar; 5(2):356.DOI: http:/ /dx.doi.org/10.18203/2349-3933.ijam20181061

[15]. Dave L, Dwivedi P, Srivastava N, Yadav BS, Dohre R. A study of cardiovascular manifestations of COPD. Int J Res Health Sci. 2014 Jul 31; 2(3): 812-7.

[16]. Kaushal M, Shah PS, Shah AD, Francis SA, Patel NV, Kothari KK. Chronic obstructive pulmonary disease and cardiac comorbidities: A cross-sectional study. Lung India: official organ of Indian Chest Society. 2016 Jul;33(4):404. DOI: 10.4103/09702113.184874

[17].Gupta AS, Rajesh V, James P. Cardiovascular comorbidities associated with patients with chronic obstructive pulmonary disease-a hospital-based study. Egyptian Journal of Bronchology. 2019 Dec 1;13(5):591DOI: 10.4103/ejb.ejb_64_19

[18]. Sushil S Anturlikar, Vaishali S Anturlikar, Dhaval K Patil.A clinical study of COPD with special reference to arrhythmia. MedPulse International Journal of Medicine. September 2019; 11(3): 175-179. DOI -https://doi.org/10.26611/10211136

[19]. Dabadghao VS, Patil R, Sharma SK, Kakrani AL. A clinical study of cardiac rhythm disturbance in patients with chronic obstructive pulmonary disease using 24 hour Holter monitoring. International Journal of Research in Medical Sciences. 2016; 4(3):1. DOI: http://dx.doi.org/10.18203/23206012.ijrms20160491

How to cite this article: Prapti Shinde, A. B. Khare, Manoj Waghmare, Marcia Waran, Arun Tyagi. AN OBSERVATIONAL STUDY OF CARDIAC INVOLVEMENT IN COPD PATIENTS AND IT'S CORRELATION WITH SEVERITY OF THE DISEASE. Int J Intg Med Sci 2020;7(2):900903. DOI: $10.16965 / \mathrm{ijims.2020.107}$ 